\title{
Evaluation of hepcidin level in chronic hepatitis C Egyptian patients undergoing regular hemodialysis
}

\author{
Yasser B. M. Ali ${ }^{1 *}$, Saad G. Moussa ${ }^{1}$, Mohammed A. Dewir ${ }^{2}$ and Ibrahim H. El-Sayed ${ }^{1}$
}

\begin{abstract}
Background: Hepcidin, an acute phase reactant released from the liver, suppresses intestinal iron uptake and release from internal stores. It is related to pathogenesis of anemia of chronic illness including anemia of chronic renal failure which is considered a chronic inflammatory state as well as HCV infection. The main purpose of this study is to evaluate level of serum hepcidin and study the possible relations between serum hepcidin and markers of iron status in chronic hepatitis C Egyptian patients on regular hemodialysis.
\end{abstract}

Results: Hepcidin was significantly elevated in hemodialysis patients than in control group $[P<0.01]$. Levels of hemoglobin, hematocrit, ferritin, and iron were significantly elevated in HCV-positive hemodialysis patients than in HCV-negative hemodialysis patients $[P<0.001]$. Hepcidin was non-significantly elevated in HCV-positive hemodialysis patients compared with HCV-negative hemodialysis patients. No significant correlations between hepcidin and any of the other studied parameters.

Conclusion: Serum hepcidin is elevated in hemodialysis patients than in control group, whereas hepcidin level is non-significantly elevated in HCV-positive hemodialysis patients compared with HCV-negative hemodialysis patients.

Keywords: Hepcidin, Iron, Hemodialysis, HCV, Erythropoietin, Egyptian

\section{Background}

Chronic kidney disease (CKD) is one of the greatest public health challenges in the twenty-first century (Becherucci, Roperto, Materassi, \& Romagnani, 2016). Prevalence is estimated to be $8-16 \%$ worldwide (Jha, Garcia-Garcia, Iseki, Li, \& Naicker, et al., 2013), and in Egypt, the estimated annual incidence of end-stage renal disease (ESRD) is around 74 per million and the total prevalence of patients on dialysis is 264 per million (El-Arbagy et al., 2016). It is a complex pathophysiological disorder which causes a significant increase in morbidity and mortality, cost of care, and decrease in quality of life. Renal anemia is a major complication in patients with CKD (Thomas et al., 2008).

Renal anemia is multifactorial: inadequate production of endogenous erythropoietin (EPO) for the degree of anemia, iron deficiency, blood loss, shortening of the

\footnotetext{
*Correspondence: Yasser.ali@gebri.usc.edu.eg

${ }^{1}$ Molecular Biology Department, Genetic Engineering and Biotechnology

Research Institute (GEBRI), University of Sadat City, Sadat 32897, Egypt

Full list of author information is available at the end of the article
}

lifespan of erythrocytes, presence of inhibitors of erythropoiesis in plasma, and vitamin deficiency (Del Vecchio et al., 2005; Mercadal et al., 2012).

The discovery of hepcidin improves our understanding about metabolism of iron (Papanikolaou et al., 2005). It suppresses intestinal iron uptake and releases from internal stores by facilitating the degradation and internalization of the only known iron exporter, ferroportin (FPN), which is expressed on the surface of enterocytes, macrophages, and hepatocytes (Babitt and Lin, 2010).

$\mathrm{HCV}$ infection is the most common blood-borne viral infection in hemodialysis; it causes significant morbidity and long-term mortality (Agarwal et al., 2009). The reported prevalence of $\mathrm{HCV}$ infection ranges from 5 to $60 \%$ in dialysis patients receiving maintenance dialysis in the developed world; the frequency of $\mathrm{HCV}$ is much higher in patients undergoing dialysis in less developed countries (Ozer Etik et al., 2015). In Egypt, the prevalence of $\mathrm{HCV}$ antibodies in hemodialysis patients ranges from 52.3 to $82.3 \%$ (Aya et al., 2010). Patients with chronic HCV infection often have increased liver iron 
(Miura et al., 2008). Iron overload syndrome and iron deposition in the liver causes organ dysfunction, cell death, fibrosis, and carcinogenesis (Nemeth, 2008).

We sought, therefore, to evaluate the level of serum hepcidin and study the possible relations between serum hepcidin and markers of iron status in chronic hepatitis $\mathrm{C}$ seropositive Egyptian patients on regular hemodialysis.

\section{Methods}

One hundred people are assigned to be involved in the present study. They consist of 80 patients receiving chronic hemodialysis for at least 1 year and were recruited from hemodialysis unit in Desouk General Hospital, Kafr El Sheikh Government, Egypt. Patients were divided into two groups: groups 1 and 2. Group 1 was for study patients and consists of 49 males and 31 females with mean age $52.26 \pm 12.28$ years. Group 1 divided into two subgroups, group 1a consists of 40 patients with hemodialysis patients with $\mathrm{HCV}$ negative which were 27 males and 13 females with mean age $51.42 \pm 2.14$ years. The second subgroup (group $1 \mathrm{~b}$ ) consists of 40 patients with hemodialysis patients with $\mathrm{HCV}$ positive which were 22 males and 18 females with mean age $53.10 \pm 1.73$ years. These patients were infected with hepatitis $\mathrm{C}$ virus (HCV) and diagnosed by the presence of $\mathrm{HCV}$ antibodies using enzyme-linked immunosorbent assay (ELISA) and confirmed to be chronically infected with $\mathrm{HCV}$ by the presence of HCV-RNA tested by real-time reverse transcription-PCR (RT-PCR). HBV antibodies were tested by using ELISA, and all patients were negative for HBV antibodies. Group 2 consists of 20 healthy patients considered as control group subjects and included in the study.

Patients excluded from the study were as follows: hemodialysis patients who were not compliant with hemodialysis for 6 months with more than three missed dialysis sessions per month, patient exposed to hospitalization, major surgeries, episodes of GI bleeding, access clotting or bacteremia, or any other infections in a 4-week period before the blood draws and pregnancy, patients with polycystic kidney disease, hepatitis B, hematopoietic disorders (including multiple myeloma), decompensated liver cirrhosis, hyperparathyroidism and/or was treated with interferon and/or ribavirin, and patients with history of blood transfusion in the last 6 months. All investigations were performed in accordance with the Menufia University, Health and Human Ethical Clearance Committee guidelines for Clinical Researchers. The local ethics committee approved the study protocol, and oral informed consents were received from all patients.

Blood samples were drawn, and the following biochemical parameter testing were measured: serum albumin level, serum total bilirubin level, serum alanine aminotransferase
(ALT) level, serum alkaline phosphatase (ALP) level, serum aspartate aminotransferase (AST) level, urea, creatinine, sodium, and potassium. Complete blood picture $(\mathrm{CBC})$, total iron, serum ferritin levels, and erythropoietin were estimated. The hepcidin level was measured by the quantitative sandwich enzyme immunoassay technique (Sun Red Company, China).

\section{Statistical analysis}

All statistical analyses were performed using SPSS (Statistical Package for Social Science) version 19. The data were presented as a mean \pm standard deviation. Two groups were compared for numerical variables by using unpaired Student's test. For non-numerical data, chi-squared tests were used for the comparison of the two groups. Correlation between variables was determined using Spearman's correlation test. A $P$ value of less than 0.05 was considered significant.

\section{Results}

\section{Patient baseline characteristics}

The baseline characteristics of the 80 chronic hemodialysis patients labeled as group 1 (40 HCV-negative patients labeled as group 1a and $40 \mathrm{HCV}$-positive patients labeled as group $1 \mathrm{~b}$ ) and 20 healthy volunteers labeled as group 2 were given in Table 1.

The HD patients were older than the healthy volunteers. There were no significant differences in gender between HD patients and healthy controls.

Among laboratory parameters in the two groups, levels of both urea and creatinine were significantly elevated in group 1 compared with group $2[P<0.001$ and $P<0.001$ for urea and creatinine, respectively. A non-significant elevation in the level of sodium between the two groups but the level of potassium was significantly elevated in group $1[P<0.001]$. Levels of liver enzymes showed a significant increase in group 1 compared with group 2 $[P<0.001$ for ALT and $P<0.001$ for AST $]$. A non-significant reduction in the level of albumin was demonstrated. Levels of both total bilirubin and alkaline phosphatase were significantly elevated in group 1 $[P<0.01$ and $P<0.05$ for total bilirubin and alkaline phosphatase, respectively] (Table 1).

Analysis of this revealed that there were elevations in renal and liver function and reduction in the level of albumin in hemodialysis patient compared with control group.

On comparing both subgroups, levels of both urea and creatinine were significantly elevated in group $1 \mathrm{~b}[P<0.001$ for both urea and creatinine]. Level of potassium was significantly elevated in group $1 \mathrm{~b}[P<0.01]$; however, a non-significant reduction in the level of sodium in the group 1b. Levels of liver enzymes showed a non-significant increase in group 1b. However, a significant reduction in the level of albumin was demonstrated $[P<0.001]$. Levels 
Table 1 Demographic and laboratory characteristics of the investigated groups

\begin{tabular}{|c|c|c|c|c|c|c|}
\hline & $\begin{array}{l}\text { Control group } \\
N=20\end{array}$ & $\begin{array}{l}\text { HD patients } \\
N=80\end{array}$ & $P$ & $\begin{array}{l}\mathrm{HCV}-\text { ve } \mathrm{HD} \\
N=40\end{array}$ & $\begin{array}{l}\mathrm{HCV}+\text { ve } \mathrm{HD} \\
N=40\end{array}$ & $P$ \\
\hline \multicolumn{7}{|l|}{ Demographic data } \\
\hline Gender (male ô/femaleo+] & $11 / 9$ & $49 / 31$ & NS & $27 / 13$ & $22 / 18$ & NS \\
\hline Age "years" & $31.55 \pm 11.02$ & $52.26 \pm 12.28$ & $<0.001$ & $51.42 \pm 2.14$ & $53.10 \pm 1.73$ & NS \\
\hline HD duration "years" & 0 & $3.55 \pm 3.608$ & $<0.001$ & $2.20 \pm 0.41$ & $4.90 \pm 0.63$ & $P<0.001$ \\
\hline \multicolumn{7}{|l|}{ Clinical profile } \\
\hline Creatinine "mg/dl" & $0.78 \pm 0.14$ & $5.37 \pm 2.54$ & $<0.01$ & $4.28 \pm 0.39$ & $6.46 \pm 0.33$ & $P<0.001$ \\
\hline Urea "mg/dl" & $24.7 \pm 7.81$ & $176.18 \pm 78.75$ & $P<0.001$ & $144.70 \pm 12.50$ & $207.65 \pm 10.33$ & $P<0.001$ \\
\hline Sodium "mmol/l" & $143.65 \pm 4.82$ & $152.64 \pm 140.68$ & $P<0.001$ & $169.97 \pm 31.24$ & $135.30 \pm 3.26$ & NS \\
\hline Potassium "mmol/l" & $3.83 \pm 0.35$ & $6.52 \pm 1.62$ & NS & $6.00 \pm 0.21$ & $7.04 \pm 0.26$ & $P<0.001$ \\
\hline$A L T$ "u/l” & $16.7 \pm 3.64$ & $23.51 \pm 7.62$ & $P<0.001$ & $22.35 \pm 1.10$ & $24.67 \pm 1.28$ & NS \\
\hline AST "u/l" & $17.45 \pm 3.87$ & $33.13 \pm 10.55$ & $P<0.001$ & $34.22 \pm 1.56$ & $32.02 \pm 1.77$ & NS \\
\hline Albumin "g/dl" & $4.05 \pm 0.29$ & $3.89 \pm 0.38$ & $P<0.001$ & $4.03 \pm 0.06$ & $3.75 \pm 0.04$ & NS \\
\hline Total bilirubin "mg/dl" & $0.65 \pm 0.13$ & $0.84 \pm 0.25$ & NS & $0.69 \pm 0.02$ & $0.98 \pm 0.04$ & $P<0.01$ \\
\hline
\end{tabular}

All data are presented as mean $\pm S D, N$ number of cases, $H D$ haemodialysis, AST aspartate aminotransferase, $A L T$ alanine aminotransferase, $T L C$ total leucocyte count, $R B C s$ red blood cells count, NS non-significant

of both total bilirubin and alkaline phosphatase were significantly elevated in group $1 \mathrm{~b}[P<0.001$ for both total bilirubin and alkaline phosphatase] (Table 1).

Analysis of this data revealed that there was an elevation in creatinine, urea, potassium, ALT, AST, total bilirubin, and alkaline phosphatase and reduction in the level of sodium, albumin, platelets, and total leucocyte count in hemodialysis patients infected with $\mathrm{HCV}$ compared with hemodialysis patients without $\mathrm{HCV}$ infection.

\section{Markers of iron status}

Iron status in patients receiving erythropoietin for dialysis-associated anemia is crucial to assure rapid and complete response to recombinant human erythropoietin (rHuEPO).
Iron status of both groups is shown in Table 2. Level of hemoglobin $(\mathrm{Hb})$ and hematocrit was significantly decreased in group 1 compared with group $2[P<0.001]$. Levels of both ferritin and iron were significantly elevated in group 1 compared with group $2[P<0.01$ and $P<0.001$ for ferritin and iron, respectively]. Hepcidin was significantly elevated in group 1 compared with group $2[P<0.01]$.

On comparing both subgroups, level of hemoglobin $(\mathrm{Hb})$ and hematocrit were significantly increased in group $1 \mathrm{~b}$ compared with group $1 \mathrm{a}[P<0.001]$. Levels of both ferritin and iron were significantly elevated in group $1 \mathrm{~b}$ than in group 1a $[P<0.001$ for ferritin and iron]. Hepcidin was non-significantly elevated in group 1b compared with group 1a (Table 2).

Table 2 Hepcidin and iron status markers of the investigated groups

\begin{tabular}{|c|c|c|c|c|c|c|}
\hline & $\begin{array}{l}\text { Control group } \\
N=20\end{array}$ & $\begin{array}{l}\text { HD patients } \\
N=80\end{array}$ & $P$ & $\begin{array}{l}\mathrm{HCV}-\text { ve } \mathrm{HD} \\
N=40\end{array}$ & $\begin{array}{l}\mathrm{HCV}+\text { ve } \mathrm{HD} \\
N=40\end{array}$ & $P$ \\
\hline \multicolumn{7}{|l|}{ Hepcidin } \\
\hline Hepcidin "ng/ml" & $338.92 \pm 88.56$ & $583.25 \pm 353.83$ & $P<0.01$ & $570.64 \pm 59.38$ & $595.86 \pm 52.96$ & NS \\
\hline \multicolumn{7}{|l|}{ Iron parameters } \\
\hline Hemoglobin "g/dl" & $12.01 \pm 1.69$ & $9.09 \pm 1.85$ & $P<0.001$ & $8.36 \pm 0.29$ & $9.81 \pm 0.24$ & $P<0.001$ \\
\hline Hematocrit "\%" & $34.47 \pm 4.17$ & $27.08 \pm 6.96$ & $P<0.001$ & $25.61 \pm 1.31$ & $28.54 \pm 0.78$ & $P<0.001$ \\
\hline MCV "fl" & $78.15 \pm 6.14$ & $85.52 \pm 7.23$ & $P<0.001$ & $83.94 \pm 1.09$ & $87.08 \pm 1.15$ & $P<0.001$ \\
\hline MCH "pg" & $27.16 \pm 2.89$ & $29.17 \pm 2.94$ & $P<0.01$ & $28.38 \pm 0.44$ & $29.96 \pm 0.45$ & $P<0.01$ \\
\hline $\mathrm{MCHC} " \mathrm{~g} / \mathrm{dl} "$ & $34.73 \pm 1.20$ & $37.95 \pm 33.60$ & NS & $33.91 \pm 0.30$ & $41.98 \pm 7.50$ & NS \\
\hline Ferritin "ng/ml" & $176.35 \pm 55.91$ & $637.69 \pm 591.11$ & $P<0.01$ & $276.77 \pm 53.66$ & $998.62 \pm 90.19$ & $P<0.01$ \\
\hline Iron " $\mathrm{gg} / \mathrm{dl} "$ & $84.20 \pm 29.85$ & $249.86 \pm 209.24$ & $P<0.001$ & $108.07 \pm 11.57$ & $391.65 \pm 32.43$ & $P<0.001$ \\
\hline Erythropoietin dos "IU/week" & 0 & $4648 \pm 1484.8$ & - & $4480 \pm 200$ & $4800 \pm 240$ & NS \\
\hline
\end{tabular}

All data are presented as mean $\pm \mathrm{SD}, \mathrm{N}$ number of cases, $H D$ haemodialysis, $M C V$ mean corpuscular volume, $M C H$ mean corpuscular hemoglobin, $M C H C$ mean corpuscular hemoglobin concentration, RBCs red blood cells count, NS non-significant 


\section{Correlation between hepcidin and iron status markers with clinical profile}

Correlation in $\mathrm{HCV}$-negative $\mathrm{HD}$ group As shown in Table 3, statistically significant positive correlations were found between iron with AST $[r=0.358, P<0.05]$ and iron with ferritin $[r=0.751, P<0.01]$, but there are no significant correlations between iron and any of the other studied parameters.

In the same essence, there were a significant positive correlation between ferritin with AST $[r=0.523, P<0.01]$, ferritin with ALT $[r=0.372, P<0.05]$, and ferritin with iron $[r=0.751, P<0.01]$. Moreover, no possible relations between ferritin and other studied parameters (Table 3).

There is no significant correlations between hepcidin and clinical profile including iron parameters, hemoglobin, hematocrit level, liver enzymes, renal function tests, and EPO dose (Table 3).

Correlation in $\mathrm{HCV}$-positive $\mathrm{HD}$ group Iron correlated negatively with EPO dose $[r=-0.501, P<0.01]$. However, iron correlated positively with ALT $[r=0.359$, $P<0.05]$ and ferritin $[r=0.784, P<0.01]$. There are no significant correlations between iron and any of the other studied parameters (Table 3).

Moreover, there was a significant negative correlation between ferritin with EPO dose $[r=-0.406, P<0.01]$. Ferritin correlated positively with ALT $[r=0.394, P<0.05]$ and HB $[r=0.374, P<0.05]$. However, no possible relations between ferritin and other studied parameters (Table 3).

In contrast, there are no significant correlations between hepcidin and any of the other studied parameters including iron parameters, hemoglobin and hematocrit level, liver enzymes, and liver function tests (Table 3).

\section{Discussion}

Hepcidin acts as a systemic iron regulatory hormone as it controls iron transport from iron exporting tissues into plasma (Ganz, 2007). Excessive hepcidin production occurs in patients with inflammatory and infectious diseases, resulting in anemia of inflammation (Nemeth et al., 2004). Anemia in end-stage renal disease (ESRD) patients may either mainly from defective EPO production by the kidneys or iron deficiency and has been reported to be correlated with the severity of disease (Nurko, 2006). HCV infection causes significant morbidity and mortality in ESRD patients on hemodialysis (Agarwal et al., 2009). Moreover, Goodkin et al., 2016 stated that it appears erroneous to assume that $\mathrm{HCV}$ infection among patients on HD can be ignored because these patients will not live long enough to develop undesirable consequences. $\mathrm{HCV}$ infection essentially goes untreated among patients on HD in 21 countries, yet it is associated with higher risks of mortality, hospitalization, liver complications, gastrointestinal bleeding, and anemia-related sequelae, as well as a variety of undesirable quality of life

Table 3 Correlation between hepcidin and iron status markers with clinical profile in hemodialysis HCV seropositive and seronegative patient

\begin{tabular}{|c|c|c|c|c|c|c|c|c|c|c|c|c|}
\hline \multirow[t]{3}{*}{ Clinical profile } & \multicolumn{6}{|c|}{$\mathrm{HCV}+$ ve HD } & \multicolumn{6}{|c|}{$\mathrm{HCV}$ - ve HD } \\
\hline & \multicolumn{2}{|l|}{ Iron } & \multicolumn{2}{|l|}{ Ferritin } & \multicolumn{2}{|c|}{ Hepcidin } & \multicolumn{2}{|l|}{ Iron } & \multicolumn{2}{|l|}{ Ferritin } & \multicolumn{2}{|c|}{ Hepcidin } \\
\hline & $R$ & $P$ value & $R$ & $P$ value & $R$ & $P$ value & $r$ & $P$ value & $r$ & $P$ value & $r$ & $P$ value \\
\hline Erythropoietin dose & $-0.501^{* *}$ & $P<0.01$ & $0.406^{* *}$ & $P<0.01$ & 0.249 & NS & 0.023 & NS & 0.272 & NS & 0.121 & NS \\
\hline $\mathrm{ALT}$ & $0.359 *$ & $P<0.05$ & $0.394^{*}$ & $P<0.05$ & -0.051 & NS & 0.226 & NS & $0.372^{*}$ & $P<0.05$ & -0.071 & NS \\
\hline AST & 0.128 & NS & 0.161 & NS & -0.063 & NS & $0.358^{*}$ & $P<0.05$ & $0.523^{* *}$ & $P<0.05$ & -0.005 & NS \\
\hline Urea & 0.112 & NS & -0.005 & NS & -0.196 & NS & -0.086 & NS & 0.128 & NS & 0.029 & NS \\
\hline Creatinine & -0.127 & NS & -0.261 & NS & -0.079 & NS & -0.214 & NS & 0.062 & NS & 0.110 & NS \\
\hline Total bilirubin & 0.002 & NS & 0.061 & NS & 0.034 & NS & -0.190 & NS & -0.129 & NS & -0.159 & NS \\
\hline ALP & 0.035 & NS & -0.027 & NS & -0.104 & NS & -0.205 & NS & -0.161 & NS & -0.067 & NS \\
\hline Albumin & -0.140 & NS & 0.054 & NS & -0.011 & NS & -0.069 & NS & -0.070 & NS & 0.324 & NS \\
\hline Potassium & 0.100 & NS & 0.044 & NS & -0.086 & NS & -0.026 & NS & 0.066 & NS & 0.066 & NS \\
\hline Sodium & -0.247 & NS & -0.177 & NS & -0.046 & NS & -0.167 & NS & -0.223 & NS & 0.081 & NS \\
\hline Iron & 1.000 & NS & $0.784^{* *}$ & $P<0.01$ & -0.22 & NS & 1.000 & NS & $0.715^{* *}$ & $P<0.01$ & 0.031 & NS \\
\hline Ferritin & $0.784^{* *}$ & $P<0.01$ & 1.000 & NS & -0.145 & NS & $0.715^{* *}$ & $P<0.01$ & 1.000 & NS & 0.071 & NS \\
\hline Hemoglobin & 0.198 & NS & $0.374^{*}$ & $P<0.05$ & -0.105 & NS & -0.139 & NS & 0.081 & NS & 0.168 & NS \\
\hline Hepcidin & -0.122 & NS & -0.145 & NS & 1.000 & NS & 0.031 & NS & 0.071 & NS & 1.000 & NS \\
\hline
\end{tabular}

AST aspartate aminotransferase, $A L T$ alanine aminotransferase, $A L P$ alkaline phosphatase, NS non-significant

${ }^{*}=P<0.05,{ }^{* *}=P<0.01$

Data in bold are significant 
scores, including greater pain and worse vitality, depression, anorexia, and pruritus.

In addition, the excessive use of IV iron products despite compliance with accepted guidelines has led to the pandemic of iron overload in ESRD population. Elevated liver tissue iron content has been shown to adversely affect the natural history of hepatitis $C$ in the general population (Rostoker and Vaziri, 2017). We aim to study the possible relations between serum hepcidin and markers of iron status in chronic hepatitis $\mathrm{C}$ seropositive Egyptian patients on regular hemodialysis.

The study was conducted on 20 healthy volunteers and 80 chronic hemodialysis patients [40 HCV-negative patients and $40 \mathrm{HCV}$-positive patients].

In the present study, it was observed that hemodialysis duration was significantly longer in $\mathrm{HCV}$-positive patients than in $\mathrm{HCV}$-negative patients, as patients with $\mathrm{HCV}$ infection spent a significantly longer time $[P<0.001]$ on hemodialysis than those without HCV infection. These findings were supported by Saifan et al., 2013.

We found that $\mathrm{HCV}$ hemodialysis patients displayed normal ALT and AST levels in comparison with HCV-negative hemodialysis patients. This agrees with the result of Contreras et al., 2007. The normality of AST and ALT activities may be due to the reduction in pyridoxal-5' -phosphate, vitamin B12, coenzyme of ALT, suppression of AST and ALT synthesis in hepatocytes, and an inhibition of AST and ALT released from the hepatocyte into the bloodstream, as well as the possibility of liver protection by the hepatocyte growth factor, which is higher in patients with chronic renal failure (LIN et al., 2008).

Serum hepcidin level measured in the present study was significantly higher $[P<0.01]$ in HD patients than in control healthy individuals group. These results came in agreement with Zaritsky and Young, 2009 and Ashby et al., 2009 which demonstrated an inverse correlation between serum hepcidin and glomerular filtration rate in adults with CKD, whereas the present data is in contrary to the recorded data of Pelusi et al., 2013 who noticed that serum hepcidin levels were not significantly different between the whole group of HD patients and controls. This elevation of hepcidin in HD patients may be related to an underlying chronic inflammation causing blood hepcidin concentrations to rise with diminishing renal function (Zaritsky and Young, 2009). High level of hepcidin was detected in the presence of chronic hepatitis C in many studies (Lin et al., 2009; Nagashima et al., 2006).

Ghoti et al., 2012 found that there is an iron overload in hepatic patient on hemodialysis for iron deposition in the liver, spleen, and in some patients in the pancreas, but not in the heart and this overload decreases after discontinuation of IV iron for 7-17 months. In the same line Rostoker et al., 2012 found that infused iron, hepcidin correlated positively and C-reactive protein correlated negatively with hepatic iron status.

In addition, the present study revealed that there is no significant difference in hepcidin level between $\mathrm{HCV}-$ ve and $\mathrm{HCV}+\mathrm{ve} \mathrm{HD}$ patients. This result came in accordance with Fujita et al., 2008 which stated that there is no relation between HCV-RNA load and serum hepcidin and supported by reported data by Ibrahim et al., 2009 which concluded that there is no significant difference in hepcidin level between $\mathrm{HCV}$ - ve and $\mathrm{HCV}$ + ve HD patients.

This may be explained by a multiplicity of factors which influence hepcidin level; thus, while inflammation, as well as treatment of anemia of HD, may increase its level, both anemia and iron deficiency may decrease its level. Moreover, infection with $\mathrm{HCV}$ may impair liver ability to secrete hepcidin which might have important implications in the treatment of anemia in hemodialysis patients infected with HCV (Ibrahim et al., 2009).

Iron and ferritin levels were higher elevated $[P<0.001$ and $P<0.01$, respectively] in HCV-positive HD patients than in HCV-negative HD patients. This result is similar to the proved data of Shan et al., 2005 who concluded that $\mathrm{HCV}$ infection is associated with higher levels of serum iron and ferritin in the US population and Zou and Sun, 2017 who stated that patients with end-stage renal disease, patients with $\mathrm{HCV}$-antibody positive appear to have higher serum iron and TS compared to patients with $\mathrm{HCV}$-antibody negative. In the same essence, Sabry et al., 2007 proved that serum iron and ferritin were higher in $\mathrm{HCV}$-positive group significant statistical difference than the negative group.

Elevated iron parameters and mild iron overload are common in the liver of patients with chronic hepatitis $\mathrm{C}$. It has been suggested that ferritin and serum iron might be correlated with liver inflammation and serum markers of fibrogenesis (Souza et al., 2006). This results also may be due to HCV infection facilitates iron accumulation or increased iron storage predisposes to $\mathrm{HCV}$ infection (Sabry et al., 2007). This explanation can be supported by positive correlation between iron, ferritin, and ALT recorded in the present study.

For hemoglobin and hematocrit, some recent studies and case reports indicated attenuated anemia in hemodialysis patients with $\mathrm{HCV}$ infection, and they previously considered this to be related to increased erythropoietin production by hepatocyte after hepatic stimulation by chronic infection with hepatitis virus (Khurana et al., 2008). This can explain our recorded data which revealed that HCV-positive HD patients have higher hemoglobin and hematocrit than in $\mathrm{HCV}$-negative $\mathrm{HD}$ patients $[P<0.001]$. On the other hand, our data disagree with Sabry, et al. 2007 
who concluded that no correlation has been found between the severity of anemia and $\mathrm{HCV}$ infection, whereas higher endogenous EPO levels were observed in these patients. The elevation of hemoglobin and hematocrit may be explained by Radovic et al., 1999 and Khurana et al., 2008 which demonstrated that serum EPO may increase after hepatitis $\mathrm{B}$ or $\mathrm{C}$ infection in $\mathrm{HD}$ patients, resulting in an improvement of red cell status.

Our results indicate that there is no significant in weekly erythropoietin (EPO) dose between HCV-positive HD patients and HCV-negative HD patients. This result came in accordance with the recorded data of Sabry et al., 2007 who found that is no change in weekly EPO dose between HCV-positive and HCV-negative HD patients, whereas the present data in contrary to the noticed data of Altintepe et al., 2004 which investigated that HCV-positive HD patients required lower weekly EPO dose than that in HCV-negative HD patients. Abdalla et al., 2000 reported higher EPO requirement in $\mathrm{HCV}$-positive $\mathrm{HD}$ patients versus $\mathrm{HCV}$-negative $\mathrm{HD}$ patients. Recorded data in this study can be explained by Sabry et al., 2007 who found that even if endogenous EPO concentration is increased, resistance to EPO action could have occurred secondary to chronic infection which impairs iron availability or perhaps suppresses erythropoiesis by humoral factors, other cytokines, or growth factors.

In an attempt to shed light on the correlations between hepcidin and both iron parameters and liver enzymes activity, we found that there was no significant correlations between hepcidin and any of the other studied parameters including iron parameters, hemoglobin and hematocrit level, liver enzymes, and liver function tests in the entire dialysis population ( $\mathrm{HCV}$ positive and negative) as well as in control group. Similar findings were reported by previous studies (Ibrahim et al., 2009; Ashby et al., 2009; Rubab et al., 2015).

Our present data disagreed with Jelić et al., 2013 who reported that hepcidin showed a significant correlation with ferritin in both a hemodialysis group and pre-dialysis group and another study of Mercadel et al., 2014 who proved that hepcidin levels were strongly related to all iron markers, particularly to ferritin in patients with any diagnosis of CKD stages 1 through 5 . In the same essence, Ibrahim et al., 2014 also noticed a significant positive correlation between serum hepcidin and serum iron, TSAT, TIBC, ferritin, hsCRP, and IL-6.

Our results regarding the correlation between hepcidin and iron parameters noted that there is no correlation between them; this may differ from results reported by some studies due to different assay methods for hepcidin which may lead to a considerable difference in results.

Tomosugi et al., 2006 and Kato et al., 2007 used mass spectrometry to measure hepcidin demonstrated a correlation between ferritin and hepcidin in HD patients. In contrast, Ashby et al., 2009 used an immunoassay to measure hepcidin levels. This may explain the fact that we did not observe this correlation in our HD patients. The small number of patients involved in our study could also be a factor. Great care needs to be exercised in correlating hepcidin concentrations determined using different methods. Astringent standardization in hepcidin measurement is required (Kroot et al., 2009).

Our recorded data can also have explained by D'Angelo., 2013 who stated that in inflammatory states, hepcidin production is no longer regulated by iron burden but is rather increased through IL-6 stimulation. Moreover, Wang et al., 2016 found that there was a significantly positive correlation between serum hepcidin levels and the level of serum ferritin in patients infected with hepatitis B virus.

\section{Conclusions}

In conclusion, there is a non-significant elevation in hepcidin levels between $\mathrm{HCV}$ - ve and $\mathrm{HCV}+$ ve HD patients and no significant correlations between hepcidin and any of the other studied parameters including iron parameters, hemoglobin and hematocrit level, liver enzymes, and liver function tests.

\section{Abbreviations \\ CKD: Chronic kidney disease; EPO: Erythropoietin; Hb: Hemoglobin; HBV: Hepatitis B virus; HCV: Hepatitis C virus; HD: Hemodialysis; rHuEPO: Recombinant human erythropoietin}

\section{Availability of data and materials}

The datasets generated and analyzed during the current study are available from the corresponding author on reasonable request.

\section{Authors' contributions}

YBMA, SGM, and IHE conceived and designed the study. YBMA and SGM participated in the experimental study and acquisition of data. MAD participated in the clinical study. YBMA analyzed and/or interpreted the data. SGM drafted the manuscript. YBMA and IHE critically revised the manuscript for important intellectual content. All authors read and approved the final manuscript.

\section{Ethics approval and consent to participate}

All investigations were performed in accordance with the Menoufia University, Health and Human Ethical Clearance Committee guidelines for Clinical Researchers, and informed consent were obtained from all subjects.

\section{Competing interests}

The authors declare that they have no competing interests.

\section{Publisher's Note}

Springer Nature remains neutral with regard to jurisdictional claims in published maps and institutional affiliations.

\section{Author details}

${ }^{1}$ Molecular Biology Department, Genetic Engineering and Biotechnology Research Institute (GEBRI), University of Sadat City, Sadat 32897, Egypt. ${ }^{2}$ Desouk General Hospital, Kafr El Sheikh Government, Desouk, Egypt. 


\section{Received: 22 December 2017 Accepted: 8 May 2018}

\section{Published online: 22 May 2018}

\section{References}

Abdalla, A. H., Owda, A. K., Fedail, H., Popovich, W. F., Mousa, D., Al-Hawas, F., ... Al-Khader, A. A. (2000). Influence of hepatitis C virus infection upon parenteral iron and erythropoietin responsiveness in regular haemodialysis patients. Nephron, 84(3), 293-294.

Agarwal, S. K., Dash, S. C., Gupta, S., \& Pandey, R. M. (2009). Hepatitis C virus infection in haemodialysis: the 'no-isolation'policy should not be generalized. Nephron Clinical Practice., (2), c133-c140.

Altintepe, L., Kurtoglu, E., Tonbul, Z., Yeksan, M., Yildiz, A., \& Turk, S. (2004). Lower erythropoietin and iron supplementation are required in hemodialysis patients with hepatitis C virus infection. Clinical Nephrology., 61(5), 347-351.

Ashby, D. R., Gale, D. P., Busbridge, M., Murphy, K. G., Duncan, N. D., Cairns, T. D., .. Maxwell, P. H. (2009). Plasma hepcidin levels are elevated but responsive to erythropoietin therapy in renal disease. Kidney International., 75(9), 976-981.

Aya, M., Sylvia, M., Taylor, Mai, E., Mostafa, K., \& Mohamed, A. (2010). Is the hepatitis $C$ virus epidemic over in Egypt? Incidence and risk factors of new hepatitis C virus infections. Liver International., 30(4), 560-566.

Babitt, J. L., \& Lin, H. Y. (2010). Molecular mechanisms of hepcidin regulation: implications for the anemia of CKD. American journal of kidney diseases., 55(4), 726-741.

Becherucci, F., Roperto, R. M., Materassi, M., \& Romagnani, P. (2016). Chronic kidney disease in children. Clinical Kidney Journal., 9(4), 583-591.

Contreras, A. M., Ruiz, I., Polanco-Cruz, G., Monteón, F. J., Celis, A., Vázquez, G., ... Ruelas-Hernández, S. (2007). End-stage renal disease and hepatitis C infection: comparison of alanine aminotransferase levels and liver histology in patients with and without renal damage. Annals of Hepatology, 6(1), 48-54.

D'Angelo, G. (2013). Role of hepcidin in the pathophysiology and diagnosis of anemia. Blood Research., 48(1), 10-15.

El-Arbagy, A. R., Yassin, Y. S., \& Boshra, B. N. (2016). Study of prevalence of endstage renal disease in Assiut governorate, upper Egypt. Menoufia Med J, 29, 222-227 [cited 2018 Mar 2] Available from: http://www.mmj.eg.net/tocd. asp?2016/29/2/222/192441/3.

Fujita, N., Sugimoto, R., Motonishi, S., Tomosugi, N., Tanaka, H., Takeo, M., ... Takei, Y. (2008). Patients with chronic hepatitis $C$ achieving a sustained virological response to peginterferon and ribavirin therapy recover from impaired hepcidin secretion. Journal of Hepatology, 49(5), 702-710.

Ganz, T. (2007). Molecular control of iron transport. Journal of the American Society of Nephrology., 18(2), 394-400.

Ghoti, H., Rachmilewitz, E. A., Simon-Lopez, R., Gaber, R., Katzir, Z., Konen, E., et al. (2012). Evidence for tissue iron overload in long-term hemodialysis patients and the impact of withdrawing parenteral iron. European Journal of Haematology, 89(1), 87-93. https://doi.org/10.1111/j.1600-0609.2012. 01783.).

Goodkin, D. A., Bieber, B., Jadoul, M., Martin, P., Kanda, E., Pisoni, R. L., et al. (2016). Mortality, hospitalization and quality of life among patients with hepatitis C infection on hemodialysis. Clinical Journal of the American Society of Nephrology. https://doi.org/10.2215/CJN.07940716.

Ibrahim, I. A., Mohamad, U. M., Darweesh, H. A., \& Rashad, A. M. (2014). Impact of hepcidin, interleukin 6 , and other inflammatory markers with respect to erythropoietin on anemia in chronic hemodialysis patients. The Egyptian Journal of Internal Medicine., 26(1), 6.

Ibrahim, M., Gadalla, H., Raslan, H., Abou Ellel, H., \& William, E. (2009). Effect of hepatitis-C virus infection on serum hepcidin in hemodialysis patients. [Ain Shams University, Egypt]. Anemia [M614]. Milano: World Congress of Nephrology.

Jelić, M., Cvetković, T., Đorđević, V., Damnjanović, G., Vlahović, P., Kocić, G., ... Antić, A. (2013). Hepcidin and iron metabolism disorders in patients with chronic kidney disease. Vojnosanitetski Pregled, 70(4), 368-373.

Jha, V., Garcia-Garcia, G., Iseki, K., Li, Z., Naicker, S., Plattner, B., ... Yang, C. W. (2013). Chronic kidney disease: global dimension and perspectives. The Lancet., 382(9888), 260-272.

Kato, A., Tsuji, T., Luo, J., Sakao, Y., Yasuda, H., \& Hishida, A. (2007). Association of prohepcidin and hepcidin-25 with erythropoietin response and ferritin in hemodialysis patients. American Journal of Nephrology., 28(1), 115-121.

Khurana, A., Nickel, A. E., Narayanan, M., \& Foulks, C. J. (2008). Effect of hepatitis C infection on anemia in hemodialysis patients. Hemodialysis International., 12(1), 94-99.

Kroot, J. J., Kemna, E. H., Bansal, S. S., Busbridge, M., Campostrini, N., Girelli, D., .. Tomosugi, N. (2009). Results of the first international round robin for the quantification of urinary and plasma hepcidin assays: need for standardization. Haematologica, 94(12), 1748-1752.

Lin, T. J., Liao, L. Y., Chou, J. M., Liu, S. O., \& Wang, C. K. (2009). Serum prohepcidin levels correlate with hepatic iron stores in chronic hepatitis $C$ patients. Hepato-Gastroenterology, 56(93), 1146-1151.

Lin, Y. L., Lin, C. W., Lee, C. H., Lai, I. C., Chen, H. H., \& Chen, T. W. (2008). Chronic hepatitis ameliorates anaemia in haemodialysis patients. Nephrology, 13(4), 289-293.

Mercadal, L., Metzger, M., Casadevall, N., Haymann, J. P., Karras, A., Boffa, J. J., ... NephroTest Study Group (2012). Timing and determinants of erythropoietin deficiency in chronic kidney disease. Clinical Journal of the American Society of Nephrology., 7(1), 35-42.

Mercadel, L., Metzger, M., Haymann, J. P., Thervet, E., Boffa, J. J., Flamant, M., ... Stengel, B. (2014). The relation of hepcidin to iron disorders, inflammation and hemoglobin in chronic kidney disease. PLoS One, 9(6), e99781.

Miura, K., Taura, K., Kodama, Y., Schnabl, B., \& Brenner, D. A. (2008). Hepatitis C virus-induced oxidative stress suppresses hepcidin expression through increased histone deacetylase activity. Hepatology, 48(5), 1420-1429.

Nagashima, M., Kudo, M., Chung, H., Ishikawa, E., Hagiwara, S., Nakatani, T., \& Dote, K. (2006). Regulatory failure of serum prohepcidin levels in patients with hepatitis C. Hepatology Research, 36(4), 288-293.

Nemeth, E. (2008). Iron regulation and erythropoiesis. Curr Opin hematology, 15(3), 169-175.

Nemeth, E., Rivera, S., Gabayan, V., Keller, C., Taudorf, S., Pedersen, B. K., \& Ganz, T. (2004). IL-6 mediates hypoferremia of inflammation by inducing the synthesis of the iron regulatory hormone hepcidin. The Journal of Clinical Investigation, 113(9), 1271-1276.

Nurko, S. (2006). Anemia in chronic kidney disease: causes, diagnosis, treatment. Cleveland Clinic Journal of Medicine., 73(3), 289-297.

Ozer Etik, D., Ocal, S., \& Boyacioglu, A. S. (2015). Hepatitis C infection in hemodialysis patients: a review. World Journal of Hepatology., 7(6), 885-895. https://doi.org/10.4254/wjh. v7. i6.885.

Papanikolaou, G., Tzilianos, M., Christakis, J. I., Bogdanos, D., Tsimirika, K., MacFarlane, J., ... Nemeth, E. (2005). Hepcidin in iron overload disorders. Blood, 105(10), 4103-4105.

Pelusi, S., Girelli, D., Rametta, R., Campostrini, N., Alfieri, C., Traglia, M., ... Messa, P. (2013). The A736V TMPRSS6 polymorphism influences hepcidin and iron metabolism in chronic hemodialysis patients: TMPRSS6 and hepcidin in hemodialysis. BMC Nephrology., 14(1), 48.

Radovic, M., Jelkmann, W., Djukanovic, L., \& Ostric, V. (1999). Serum erythropoietin and interleukin-6 levels in hemodialysis patients with hepatitis virus infection. Journal of Interferon \& Cytokine Research, 19(4), 369-373.

Rostoker G, Griuncelli M, Loridon C, Couprie R, Benmaadi A, Bounhiol C et al. Hemodialysis-associated hemosiderosis in the era of erythropoiesisstimulating agents: a MRI study. The American Journal of Medicine 2012; 125(10):991-999. e1. doi: https://doi.org/10.1016/j.amjmed.2012.01.015))

Rostoker, G., \& Vaziri, N. D. (2017). Impact of iatrogenic iron overload on the course of hepatitis $C$ in dialysis population: a plea for caution. Hemodialysis Int, 21(suppl 1), S68-S77.

Rubab, Z., Amin, H., Abbas, K., Hussain, S., Ullah, M. I., \& Mohsin, S. (2015). Serum hepcidin levels in patients with end-stage renal disease on hemodialysis. Saudi Journal of Kidney Diseases and Transplantation., 26(1), 19.

Sabry, A., El-Dahshan, K., Mahmoud, K., El-Husseini, A., Sheashaa, H., \& Abo-Zenah, H. (2007). Effect of hepatitis C virus infection on haematocrit and haemoglobin levels in Egyptian hemodialysis patients. European Journal of General Medicine., 4(1), 9-15 https://doi.org/10.29333/ejgm/82414.

Saifan, C., El-Charabaty, E., Kleiner, M., \& El-Sayegh, S. (2013). Effect of hepatitis C virus infection on erythropoiesis in patients on hemodialysis. International Journal of Nephrology and Renovascular Disease., 6, 121.

Shan, Y., Lambrecht, R., \& Bonkovsky, H. (2005). Association of hepatitis C virus infection with serum iron status: analysis of data from the third National Health and Nutrition Examination Survey. Clinical Infectious Diseases., 40(6), 834-841.

Souza, R. M., Freitas, L. A., Lyra, A. C., Moraes, C. F., Braga, E. L., \& Lyra, L. G. (2006). Effect of iron overload on the severity of liver histologic alterations and on the response to interferon and ribavirin therapy of patients with hepatitis C infection. Brazilian journal of medical and biological research., 39(1), 79-83.

Thomas, R., Kanso, A., \& Sedor, J. R. (2008). Chronic kidney disease and its complications. Primary Care, 35(2), 329-vii. https://doi.org/10.1016/j.pop. 2008.01.008. 
Tomosugi, N., Kawabata, H., Wakatabe, R., Higuchi, M., Yamaya, H., Umehara, H., \& Ishikawa, I. (2006). Detection of serum hepcidin in renal failure and inflammation by using ProteinChip System. Blood, 108(4), 1381-1387.

Del Vecchio, L., Pozzoni, P., Andrulli, S., \& Locatelli, F. (2005). Inflammation and resistance to treatment with recombinant human erythropoietin. Journal of renal nutrition., 15(1), 137-141.

Wang, J., Dong, A., Liu, G., et al. (2016). Correlation of serum hepcidin levels with disease progression in hepatitis B virus-related disease assessed by nanopore film based assay. Scientific Reports, 6, 34252. https://doi.org/10. 1038/srep34252.

Zaritsky, J. J., \& Young, B. Y. (2009). The utility of multivariate analysis in the study of hepcidin. Kidney International., 76, 912.

Zou, D.-M., \& Sun, W.-L. (2017). Relationship between hepatitis C virus infection and iron overload. Chinese Medical Journal., 130(7), 866-871. https://doi.org/ 10.4103/0366-6999.202737.

\section{Submit your manuscript to a SpringerOpen ${ }^{\bullet}$ journal and benefit from:}

- Convenient online submission

- Rigorous peer review

- Open access: articles freely available online

- High visibility within the field

- Retaining the copyright to your article

Submit your next manuscript at $>$ springeropen.com 